\title{
O ESTUDO DAS PRÁTICAS FUNERÁRIAS COM OS INDIVÍDUOS INFANTIS NO SíTIO ARQUEOLÓGICO LAJEDO DO CRUZEIRO, POCINHOS, PARAÍBA
}

\author{
Bruno Manoel Lima ${ }^{i}$ \\ Tatiane Maria Soares ${ }^{\mathrm{ii}}$
}

Flávio Augusto de Aguiar Moraes iii

' UFAL - Campus do Sertão, email: limabbruno@hotmail.com

iUFS - Campus de Laranjeiras, email: tat.msoarez@gmail.com

iiiUFAL - Campus do Sertão, email: flavioaguiarac@gmail.com
Resumo: Os estudos acerca da presença de indivíduos infantis, no campo das práticas funerárias dos grupos pré-históricos do Nordeste brasileiro é algo que vem crescendo gradativamente na discussão arqueológica. Poucos são os trabalhos produzidos que abordam essa temática. Uma vez que o pesquisador enfrenta dificuldades e limitações ao desenvolver sua pesquisa, sendo elas a má conservação dos ossos, por se tratar de um indivíduo não adulto e sua degradação no contexto encontrado. Sendo assim, o referido trabalho objetiva apresentar algumas reflexões iniciais sobre as práticas funerárias utilizadas para com os indivíduos infantis que foram identificados no sítio Lajedo do Cruzeiro, Pocinhos/PB pelo Núcleo de Pesquisa e Estudos Arqueológicos e Históricos - NUPEAH da Universidade Federal de Alagoas - Campus do Sertão. Adotando uma análise centrada na preservação, identificação e sinais de manipulação: esfolamento, descarnamento, desarticulação e raspagem a partir dos parâmetros metodológicos propostos por Botella et al. (2000). Palavras-Chaves: Práticas Funerárias; Sepultamentos Infantis; Lajedo do Cruzeiro.

Abstract: Studies around the presence of infantile individuals in the field of funerary practices of prehistoric groups in Bralizian northeastern, has been growing gradually in archaeological discussion. There are few studies that address this theme. The researcher faces difficulties and limitations in developing his research, being the bad conservation of bones, because it is a nonadult individual and its degradation in the context found. Thus, this paper aims to present some initial reflections on the funerary practices used with children who were identified in the farm Lajedo do Cruzeiro, Pocinhos / PB by the Center for Research and Archaeological and Historical Studies - NUPEAH of the Federal University of Alagoas - Campus do Sertão. Adopting an analysis focused on preservation, identification and signs of manipulation: skinning, stripping, disarticulation and scraping from the methodological parameters proposed by Botella et al. (2000). Keywords: Funerary Practices; Borials infantiles; Lajedo do Cruzeiro site. 


\title{
Introdução
}

A Arqueologia da Morte surge no contexto da Arqueologia Processual, a partir da década de 1960, implementando nos estudos arqueológicos novas perspectivas teórico-metodológicas para compreender as práticas funerárias elaboradas pelos grupos do passado (Alcina Franch, 1989; Renfrew e Bahn, 1998; Trigger, 2004; Ribeiro, 2007).

Dessa forma, o contexto funerário poderá oferecer o entendimento de uma grande variedade de informações como:

\begin{abstract}
Aspectos biológicos (sexo, idade), preparação e tratamento do corpo (tipo de disposição, posição), características da sepultura (forma, dimensão, profundidade), acompanhamentos funerários (variedades, quantidades, formas), localização (área do enterramento, distribuição espacial dentro do sítio) e aspectos ambientais (condições ambientais ao tempo do enterramento, através dos vestígios de polens e insetos) (Cisneiros, 2004, p. 42).
\end{abstract}

Os estudos sobre as práticas funerárias em sítios arqueológicos focam em duas linhas de pesquisa: os estudos voltados para os dados biológicos, que tem como objetivo compreender os dados relacionados aos sepultamentos; e os estudos voltados para os dados culturais, destinados a análise da variabilidade cultural e estilística da cultura material produzida por esses povos pretéritos, por exemplo, como os acompanhamentos funerários (Ribeiro, 2007).

Soares (2019) faz o levantamento bibliográfico de pesquisas arqueológicas que foram desenvolvidas em sítios de contexto funerário pré-histórico no nordeste brasileiro. A pesquisadora elenca por Estado todos os sítios identificados na literatura e as respectivas pesquisas desenvolvidas. Os sítios foram caracterizados tendo em vista alguns parâmetros, tais como a localização dos sítios (sertão, agreste ou litoral), município, estado, cronologia, e os materiais associados. Segundo a autora, identificaram-se através desse levantamento bibliográfico os seguintes sítios:

Sítio São José II, Delmiro Gouveia - Alagoas (Carvalho e Vergne, 2001); sítio Justino, Canindé de São Francisco - Sergipe (Santos, 2007; Fagundes, 2010; Santana, 2013; Santana e Carvalho, 2013; Silva e Carvalho, 2013; Silva, 2013, 2017; Oliveira e Klokler, 2017; Queiroz et al, 2017); sítio Furna do Estrago, Brejo da Madre de Deus - Pernambuco (Montardo, 1995; Santos, 2006; Menezes e Queiroz, 2006; Castro, 2009, 2018; Leite et al, 2014; Silva, 2015; Fontes, 2016; Souza, 2018); sítio Pedra do Caboclo, Bom Jardim Pernambuco (Leite et al, 2014); sítio Cemitério do Caboclo, Venturosa Pernambuco (Cisneiros, 2004; Amaral, 2007; Leite et al, 2014; Perazzo et al, 2017); sítio PE 91-Mxa, Buíque - Pernambuco (Leite et al, 2014; Cisneiros, 
2004); sítio Alcobaça, Buíque - Pernambuco (Nascimento et al, 1996; Cisneiros, 2004; Leite et al, 2014); Gruta do Padre, Itaparica - Pernambuco (Oliveira, 1942, Etchevarne,1999-2000; Martin, 1994); sítio Pedra do Alexandre, Carnaúba dos Dantas - Rio Grande do Norte (Martin, 1995; Ramos, 1996; Cisneiros, 2004; Mutzenberg, 2007; e Solari et al, 2016) e sítio Furna dos Ossos, Santana dos Matos - Rio Grande do Norte (Lima et al, 2017) (Soares, 2019. p. 20-21).

\section{A Presença Infantil nos Sepultamentos Secundários do Nordeste Brasileiro}

A região do Nordeste brasileiro foi expressamente ocupada durante o período pré-histórico, o que pode ser comprovado, pelos estudos arqueológicos já realizados em diversos estados. A presença de sepultamentos humanos está presente, em maiores proporções, nas regiões do Piauí, Serra da Capivara; Rio Grande do Norte, na área do Seridó; Pernambuco, no sítio arqueológico Furna do Estrago; na Paraíba com o sítio Lajedo do Cruzeiro e em Sergipe com o sítio Justino. Outros sítios arqueológicos com presença de sepultamentos humanos estão localizados na região do Nordeste Brasileiro: em Alagoas, São José II, Delmiro Gouveia. Em Pernambuco, Brejo da Madre de Deus; Pedra do Caboclo, Bom Jardim; Cemitério do Caboclo, Venturosa; PE 91-Mxa, Buíque; sítio Alcobaça, Buíque; Gruta do Padre, Itaparica. No Rio Grande do Norte, em Carnaúba dos Dantas e Furna dos Ossos, em Santana dos Matos.

Na região Nordestina, a presença dos registros infantis nos debates arqueológicos e as pesquisas realizadas vem ganhando espaço gradativamente, os poucos trabalhos desenvolvidos na área é uma comprovação. Através do levantamento bibliográfico da região do Nordeste Brasileiro, os trabalhos com enfoque nos indivíduos não adultos, entre eles são, o trabalho intitulado "Presença infantil no registro Bioarqueológico no sítio Pedra do Alexandre, Carnaúba dos Dantas, RN, Brasil, 2016" de Solari et al. (2016), que aborda uma discussão acerca das práticas funerárias realizadas com os indivíduos não adultos no sítio Pedra do Alexandre e o registro arqueológico através da sua presença. Silva e Carvalho (2013) com o trabalho "Análise Arqueotanatológica de duas sepulturas infantis - Sítio Justino-SE", que busca compreender a deposição do esqueleto no ato do sepultamento através dos parâmetros metodológicos da Arqueotanatologia. No trabalho "Análise antropológica em sepultura de criança do Sítio São José II, Delmiro Gouveia, Estado De Alagoas", Fontes et al. (2012) traz uma discussão antropológica através da análise de uma sepultura de criança encontrada no sítio São José II. Já no trabalho "Análise macroscópica das alterações no esmalte dentário e dieta dos indivíduos subadultos enterrados no Sítio Arqueológico Furna do Estrago, PE - 2017" de 
Oliveira (2017) se discute a relação social entre as crianças e os adultos da Furna do Estrago, através da análise do esmalte dos dentes e as alterações sofridas como consequência da alimentação.

O menor número de trabalhos que tem um enfoque na presença da criança, sobretudo, enquanto um ser ativo na sociedade em que viveu (Oliveira, 2017) é consequência de vários fatores que vem a limitar os estudos dos indivíduos infantis dentro do registro arqueológico, seja pela má preservação dos remanescentes ósseos e sua complexidade morfológica, ou até mesmo por sua ausência dentro do contexto arqueológico (Solari et al., 2016).

\section{Método}

Através dos estudos acerca da literatura arqueológica, produzidas até os dias atuais, que se debruçam sobre a análise das manipulações intencionais no contexto funerário em outros sítios arqueológicos, como na Pedra do Cachorro (Solari et al., 2017), e o padrão 2 do sítio Lapa do Santo (Strauss, 2010, 2014, 2016), que apresentam sepultamentos com manipulações intencionais, com características semelhantes ao do sítio Lajedo do Cruzeiro. Desta forma, será apresentada uma discussão comparativa das práticas realizadas no rito funerário, sobretudo nos casos de manipulações antrópicas dos sítios apresentados e suas variabilidades.

Os atributos definitivos para a análise desta pesquisa foram a observação dos materiais osteológicos dos indivíduos infantis (Schaefer et al., 2009). Observando os fatores oriundos dos sinais de manipulações realizadas intencionalmente, como exemplo, as marcas de corte presentes nas extremidades epifisiais dos ossos longos, como uma possível prática de redução do corpo na realização do rito funerário e seu sepultamento (Solari, 2017). Para realização das análises, foram utilizados os parâmetros metodológicos propostos por Botella et al. (2000). Buscando identificar a preservação e identificação dos sinais feitos de forma intencional: esfolamento, descarnamento, desarticulação e raspagem.

Portanto, para Botella et al. (2000), as marcas de esfolamento resultam sinais que permanecem registrados nos ossos, sendo consequência da objetivação do corte da pele para separá-la do corpo. Sendo assim, é uma marca que só é possível perceber através da proximidade da pele com o osso, e que a presença de tais marcas se apresenta abundantemente mais visíveis na área do crânio. Pode variar também em aspectos de profundidade, a depender do instrumento utilizado. 
Segundo o autor, os sinais de desarticulação, diferentes dos de esfolamento, resultam em incisões marcadas nos ossos, fruto de uma possível separação do osso e a carne mole, objetivando separar os segmentos corporais geralmente através das áreas Peri articulares, localizadas assim nas extremidades dos ossos longos ou em zonas condizentes a inserções musculares. A desarticulação é realizada mediante cortes, procurando uma separação dos membros, e suas marcas consistem em incisões transversais paralelas ou perpendiculares, podendo ser únicas e múltiplas longas, sempre com secção em " $\mathrm{V}$ ".

Por sua vez, Botella et al. (2000), define o descarnamento como um procedimento de remoção das massas musculares (carnes moles), fazendo com que a parte cortante do instrumento cause as incisões sobre o osso, ao apoiar-se. Suas marcas tratam de incisões continuas demonstrando secções em " $V$ ", e podem aparecer em qualquer parte do osso, exceto nas zonas articulares. As incisões e espessura são variáveis, tendo em vista que sofrem influência do tipo de instrumento utilizado e a força aplicada na realização.

E, finalmente, as marcas de raspagem para Botella et al. (2000), são oriundas da remoção do periósteo ou limpeza das áreas ligamentosas, caracterizada por inúmeras estrias, de traços desproporcionais nas superfícies externa dos ossos. Os sinais caracterizados se apresentam de formas finas, lineares e múltiplos, também com secções em " $V$ ", no entanto, de forma pouco extensas e rasas, podendo ser agrupadas, sobrepostas, repetidas ou entrecruzadas.

Os materiais osteológicos, que foram identificados no sítio Lajedo do Cruzeiro, e utilizados no presente trabalho, passaram pelo processo de análise e registro fotográfico, no laboratório do Núcleo de Pesquisas e Estudos Arqueológicos Históricos - NUPEAH, que se encontra localizado na Universidade Federal de Alagoas - Campus do Sertão, atividade esta que foi coordenada e acompanhada pelo Arqueólogo e coordenador do núcleo Flávio Augusto de Aguiar Moraes.

\section{Contextualização Histórica do Munícipio de Pocinhos/PB}

O município de Pocinhos está localizado no Cariri Paraibano. A população estimada em 2018, segundo o IBGE, era de 18.429 pessoas. Segundo Soares (2019), o nome do município originou-se a partir de diversos poços contendo água potável onde os primeiros moradores da cidade se instalaram fundando uma capela e uma fazenda nas proximidades. 


\section{Sítio Arqueológico Lajedo do Cruzeiro/PB}

O sítio foi categorizado como um abrigo sob rocha (Figura 1 ) onde foi verificado material cerâmico (Figura 2) e ósseo em superfície (Figura 3), bem como a presença de enterramento secundário coletivo, com indivíduos de diversas faixas etárias, assim como a presença de acompanhamentos funerários do tipo adornos, como as contas de colar em ossos de animais e madeira (Soares, 2019).

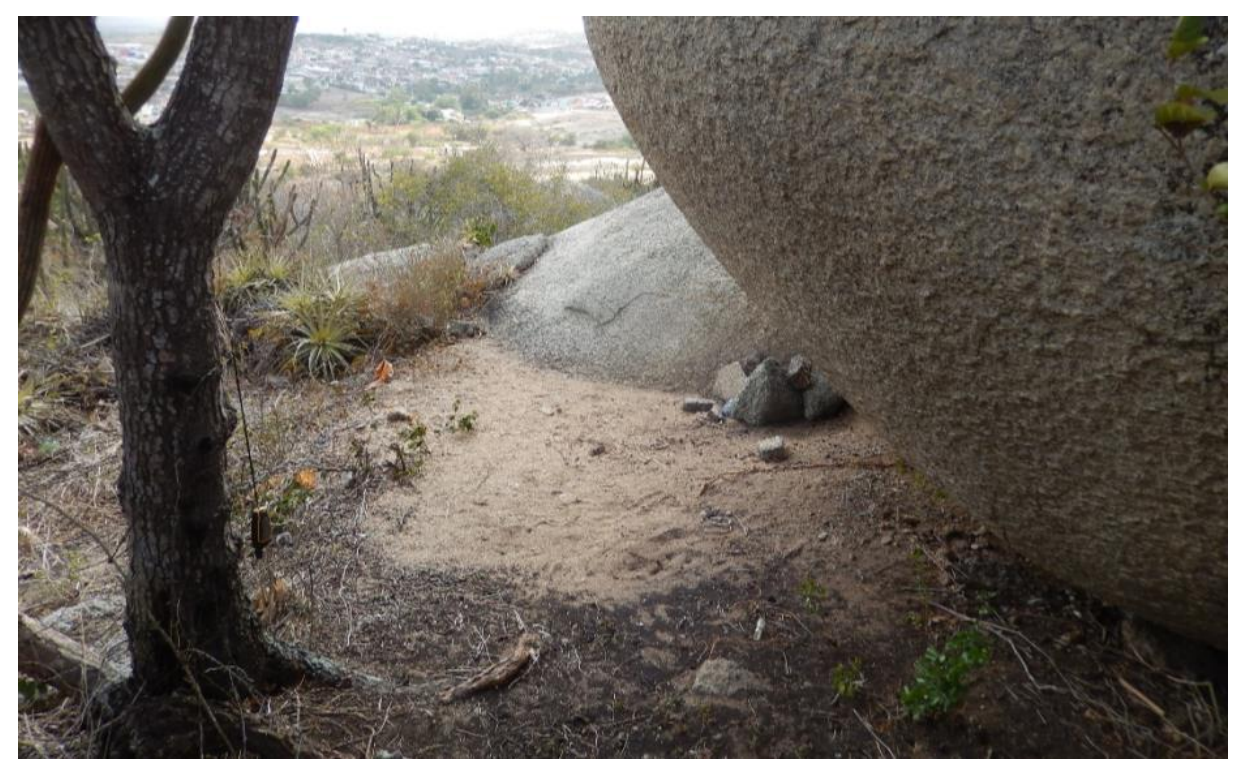

Figura 1: Área do sitio arqueológico Lajedo do Cruzeiro. Foto do acervo do NUPEAH (2017).

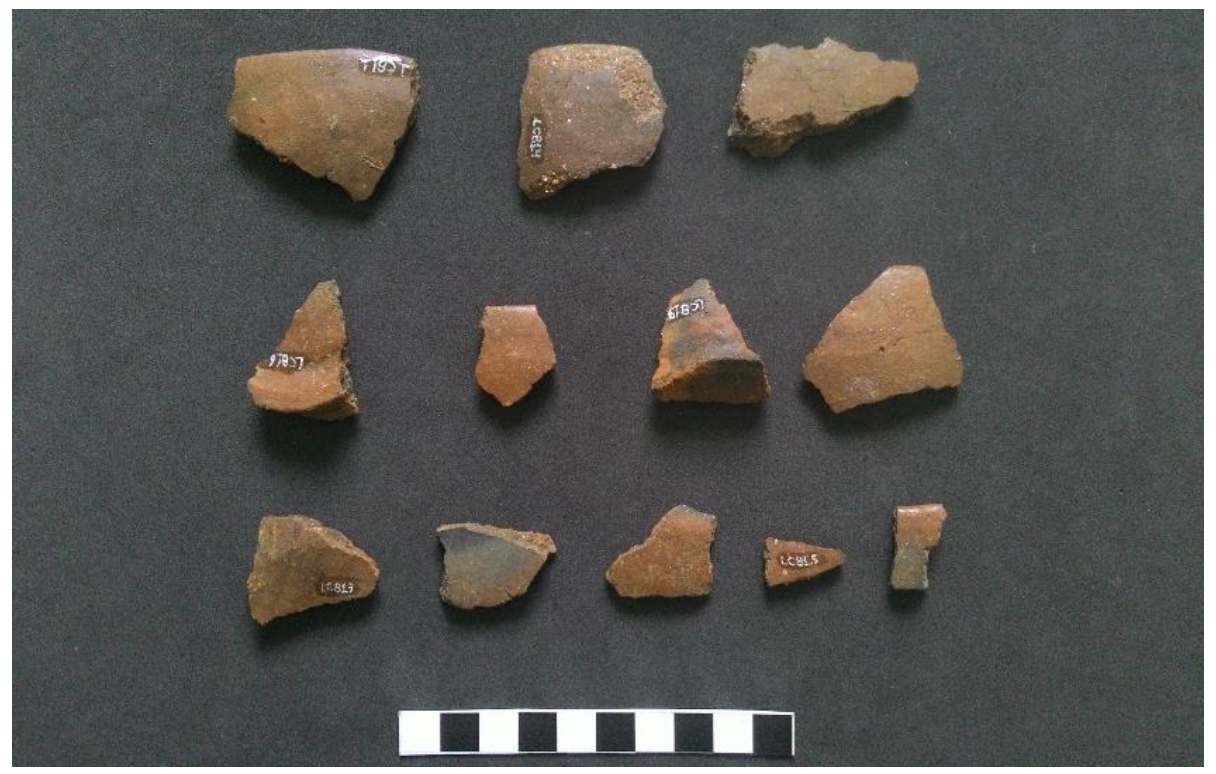

Figura 2: Material cerâmico coletado durante as escavações. Foto do acervo do NUPEAH (2017). 


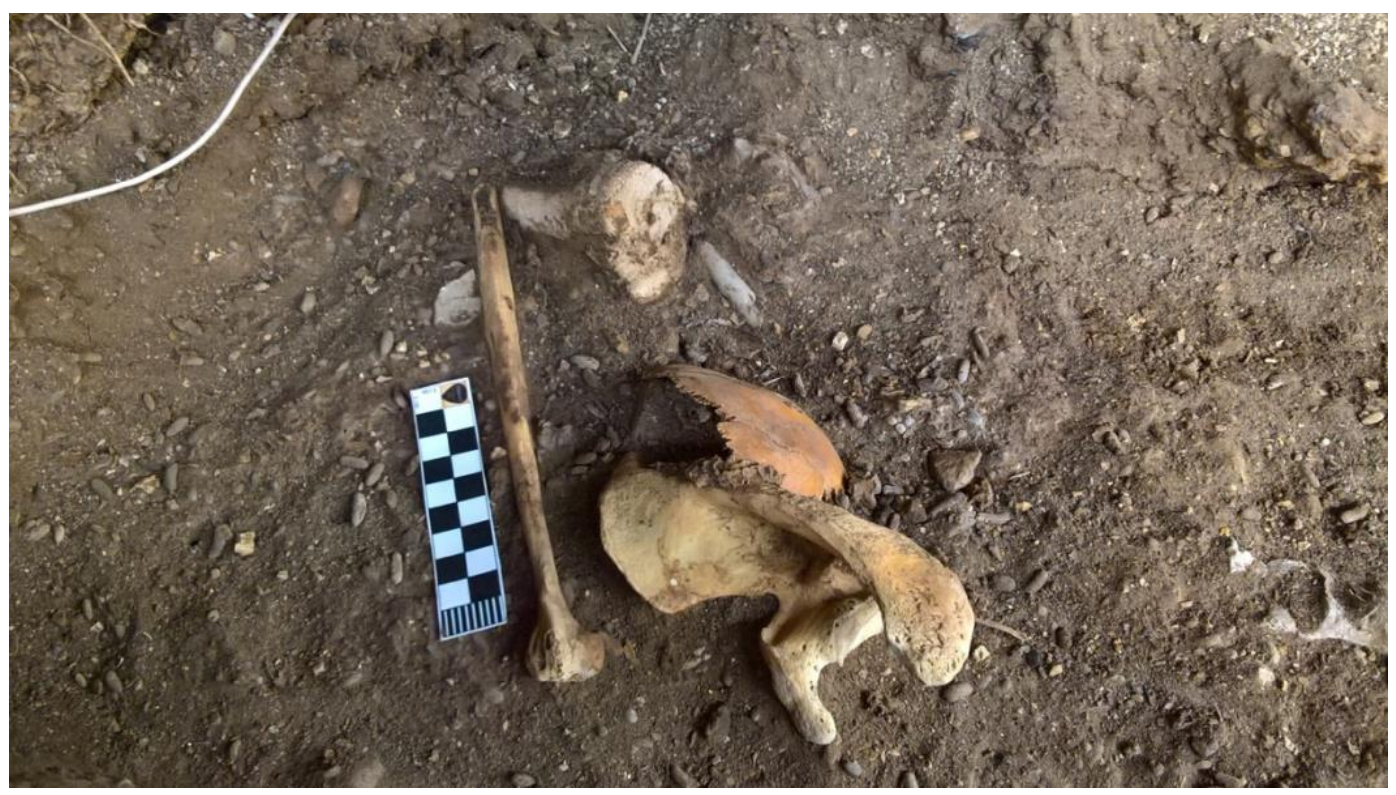

Figura 3: Material osteológico humano sendo evidenciado durante as escavações. Foto do acervo do NUPEAH (2017).

Soares (2019) faz a caracterização do sítio Lajedo do Cruzeiro, localizado no município de Pocinhos/Paraíba que foi identificado em 2015, através dos arqueólogos vinculados ao Instituto Memorial da Borborema e Núcleo de Pesquisa e Estudos Arqueológicos e Históricos da Universidade Federal de Alagoas, Campus do Sertão - Delmiro Gouveia, com o início das escavações (Figura 4) no ano de 2017.

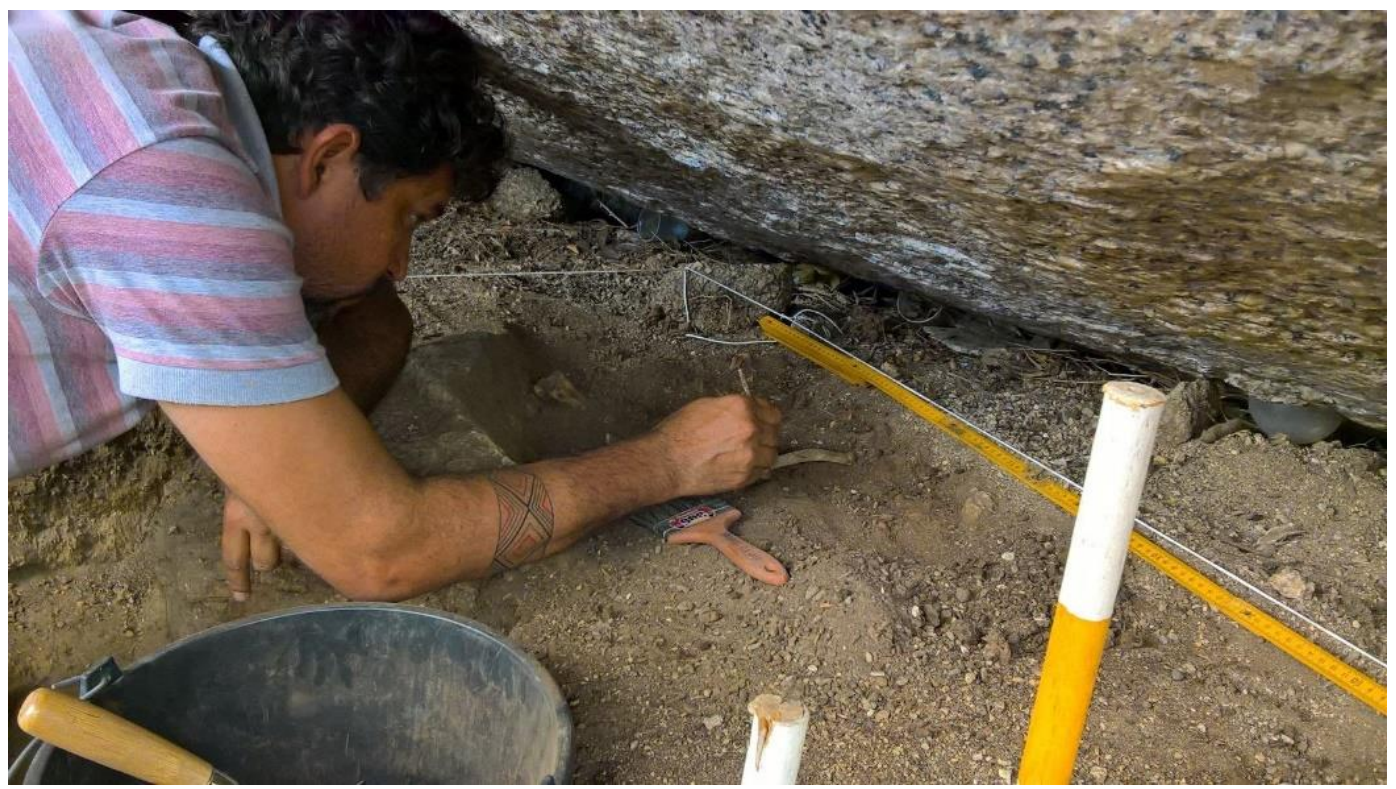

Figura 4: Escavação do sitio arqueológico Lajedo do Cruzeiro. Foto do acervo do NUPEAH (2017). 
A pesquisadora Tatiane Maria Soares em sua monografia "Acompanhamentos Funerários do sítio Lajedo do Cruzeiro - Pocinhos/PB: Identificação e Caracterização das contas de colar e pingente" (2019) analisou os adornos do sítio Lajedo do Cruzeiro/PB a fim de compreender os dados culturais dos grupos que organizaram tais eventos relacionados sobre a morte nesse sítio. Sua pesquisa teve como objetivo identificar e caracterizar as contas de colar e pingente, as análises buscaram compreender quais as preferências de matéria prima e técnicas de confeç̧ão utilizadas na elaboração desses objetos de adorno pessoal. Foram analisados 18 objetos confeccionados a partir de materiais diversificados categorizados como adornos.

Isso posto, os estudos e discussões acerca do sítio arqueológico Lajedo do Cruzeiro e sua contribuição para analisar e compreender as práticas funerárias na região do Nordeste brasileiro vem se desenvolvendo, sobretudo, por apresentar características e práticas não muito comuns como a redução de corpos nos rituais funerários do Nordeste (Solari et al, 2017). Sendo assim, o sítio arqueológico aqui trabalhado, traz consigo uma diversidade de informações acerca de como os povos pretéritos enfrentavam a morte e preparavam o cadáver dos seus entes, compreendendo que diversas eram as maneiras e práticas de lhe dar com o fenômeno da morte, diferenciando-se de povo, cultura, região dentre outros fatores.

\section{Resultados Parciais}

Foram analisadas 07 extremidades epifisiais de ossos longos, de indivíduos infantis, que apresentaram marcas de cortes e consequentemente sinais de manipulação humana perimortem provenientes de um sepultamento coletivo entre adultos e não adultos evidenciados nas escavações no sitio Lajedo do Cruzeiro (Figura 5). Foram analisados e categorizados a partir dos procedimentos metodológicos propostos por (Botella et al. 2000), nas especificidades de sinais de manipulação humana (marcas de corte) em: esfolamento, descarnamento, desarticulação e raspagem.

Preliminarmente, nos resultados de análise, os materiais ósseos analisados, extremidade distal do rádio esquerdo (Figura 6), extremidade distal do úmero direito (Figura 7), epífise proximal da ulna direita (Figura 8) e epífise proximal da fíbula direita (Figura 9), demonstraram sinais de desarticulação apresentando incisões transversais com secção em " $\mathrm{V}$ " marcados nos ossos resultantes desse procedimento. A desarticulação busca separar os segmentos corporais pelas juntas ou articulações, geralmente localiza-se nas extremidades dos ossos longos. 


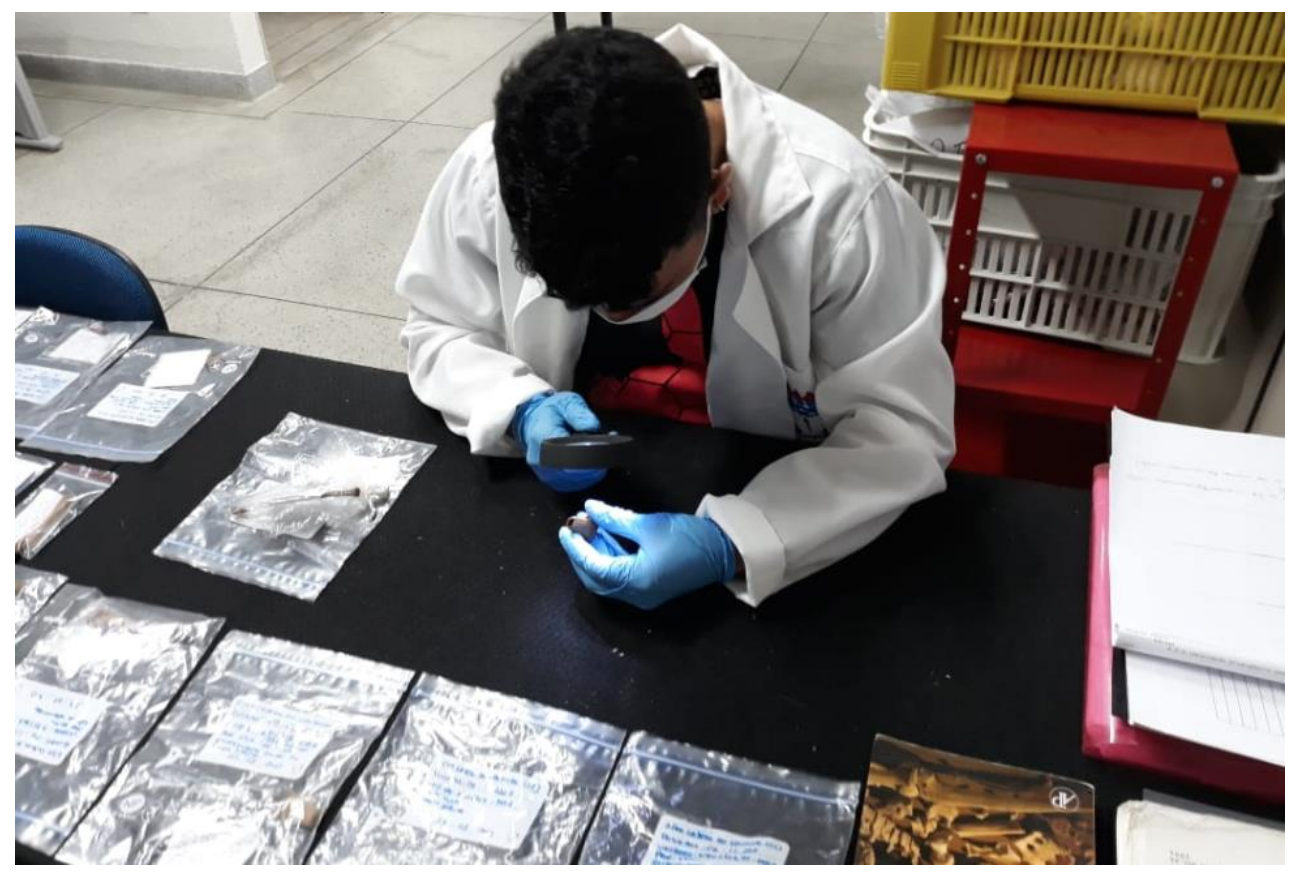

Figura 5: Utilização de lupa para análise de marcas de corte nas extremidades dos ossos longos.

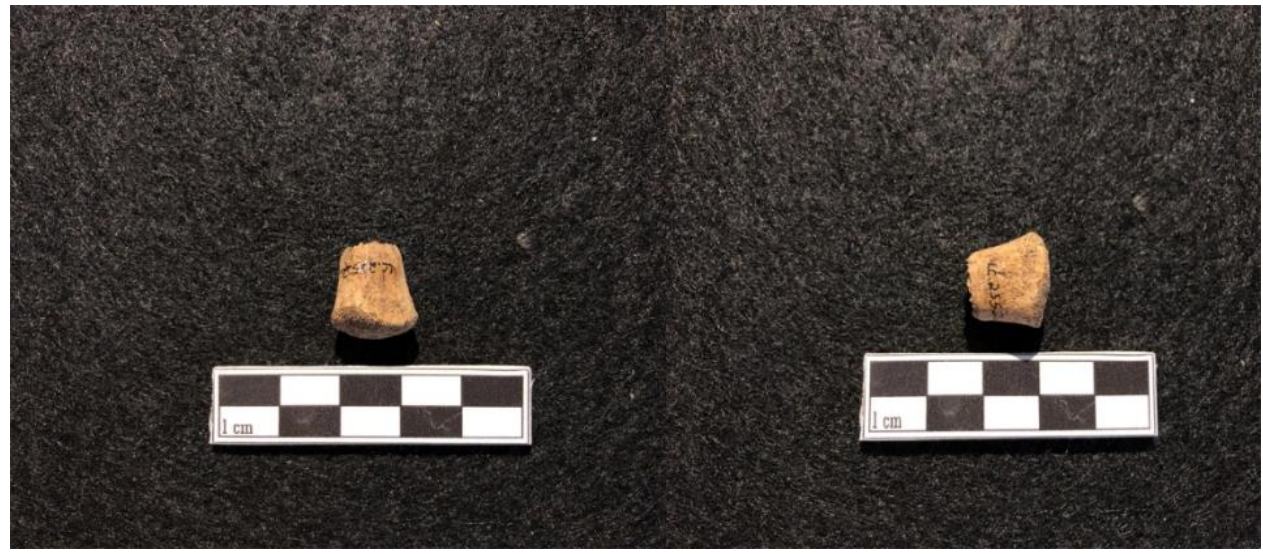

Figura 6: Extremidade distal do rádio esquerdo infantil com marcas de cortes e secções em "V". Foto do acervo do NUPEAH (2019).

Todo o material analisado mantém uma única característica de manipulação, uma ação de desarticulação através das áreas peri articulares e mais presentes nas extremidades dos ossos longos, seguindo assim um padrão. Nesse caso, os materiais analisados são de indivíduos infantis, o que se pode chegar a uma prática recorrente de redução de corpos e sepultamentos coletivos como tratamento do cadáver nos rituais funerários, seja com aqueles indivíduos adultos ou não adultos dentro do próprio grupo, não havendo assim, uma distinção de tratamento quanto a sua faixa etária. 


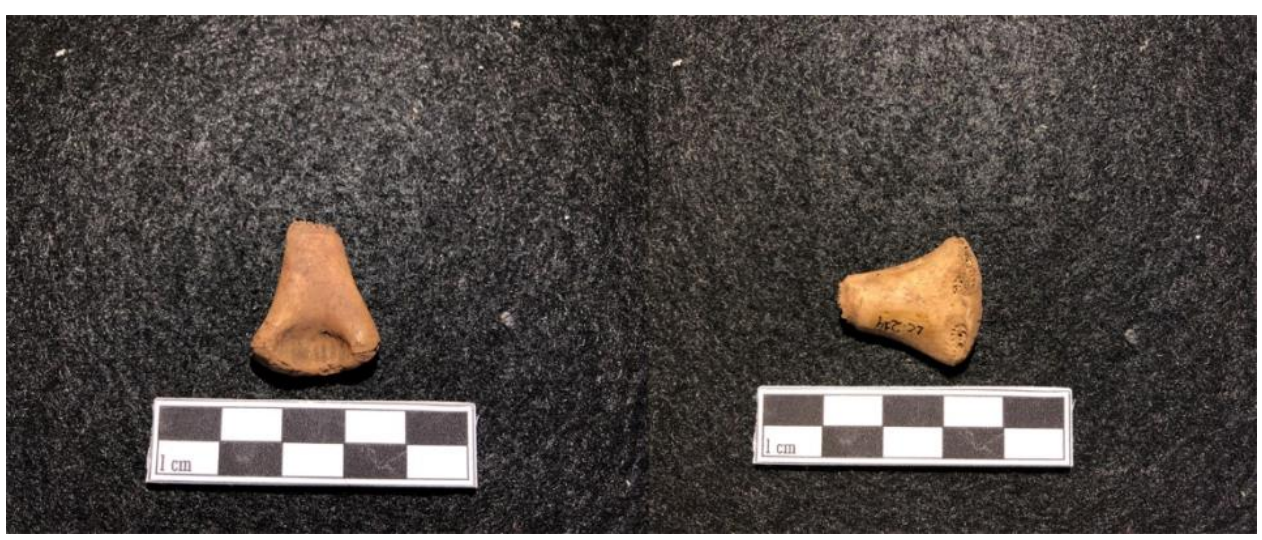

Figura 7: Extremidade distal do úmero direito infantil com sinais de marca de cortes, desarticulação intencional e secções em "V". Foto do acervo do NUPEAH (2019).

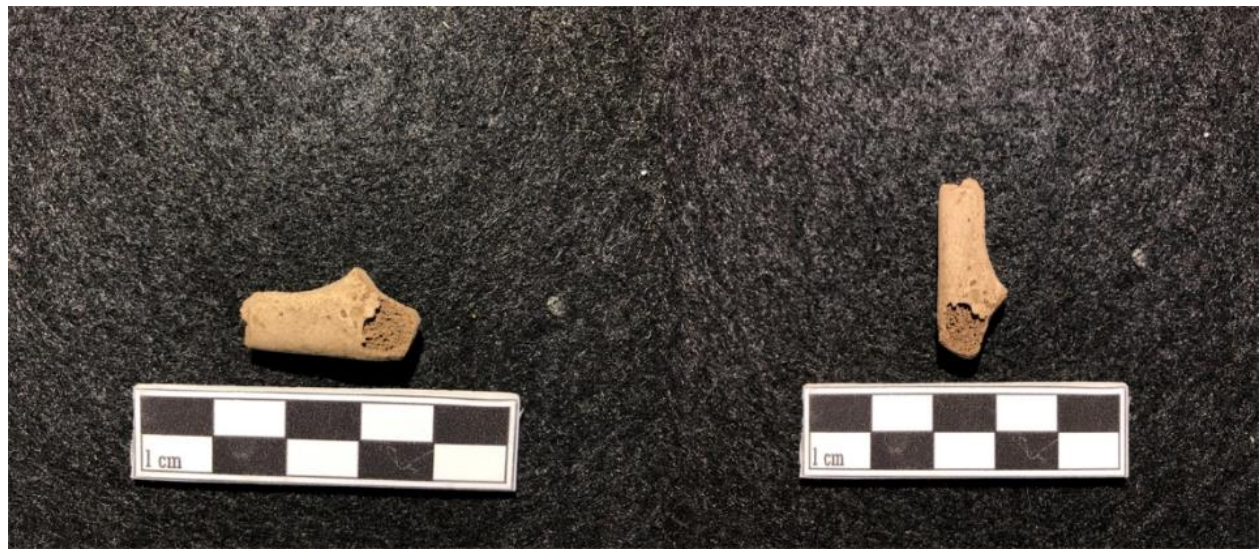

Figura 8: Epífise proximal da ulna direita infantil com marcas de corte provenientes de manipulação humana. Foto do acervo do NUPEAH (2019).

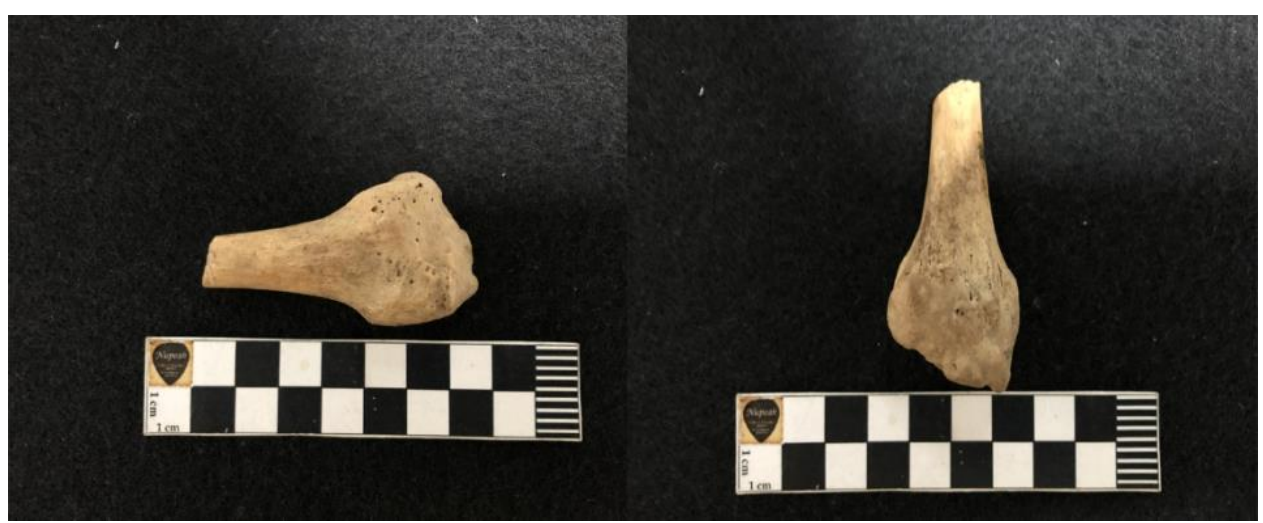

Figura 9: Epífise proximal da fíbula direita de individuo não adulto com sinais de marcas de corte. Foto do acervo do NUPEAH (2019). 


\section{Discussão}

Os trabalhos realizados sobre as práticas funerárias relacionados a sítios pré-históricos, e que se debruçam sobre as manipulações intencionais no contexto funerário, produzidos até o momento, pode-se mencionar o sítio Pedra do Cachorro (Solari et al. 2017), e o sítio arqueológico Lapa do Santo em Minas Gerais (Strauss 2010, 2014, 2016). Um número de pesquisas muito reduzido, o que não descarta a possibilidade de que outros sítios préhistóricos possam conter material com características semelhantes aos aqui apresentados e analisados.

Os materiais analisados do enterramento coletivo do sítio Lajedo do Cruzeiro, se comparado aos sepultamentos do sítio Pedra do Cachorro e o padrão 2B do sítio Lapa do Santo, demonstra características de manipulações intencionais, como a desarticulação do corpo, semelhantes ao que foi identificado em ambos os sítios, como uma prática facilitadora ou até mesmo totalmente simbólica para o enterramento.

Ossos de cadáveres que passaram por um procedimento de redução ou práticas costumeiras na preparação do corpo, e que a partir da análise do contexto mortuário, nos aproximam da reconstrução ritualística que esses povos utilizavam, e sua concepção acerca da morte e como a enfrentam a depender dos seus fatores sociais e culturais, que pode divergir de um determinado grupo para outro, embora habitem a mesma região.

\section{Considerações Parciais}

Analisar as práticas funerárias dentro do contexto arqueológico é tentar reconstruir o momento do ritual funerário realizado pelos povos pretéritos que ali habitaram. É buscar compreender através de suas práticas, seus valores culturais, sociais e crenças atrelados ao fenômeno da morte, o qual sempre esteve presente em todos os lugares. Mais do que isso, é também identificar a forma para que seus entes queridos permanecessem vivos socialmente na memória daquele povo, e o valor simbólico e sentimental que cada ritual trazia consigo.

Portanto, as formas de enterramentos trazem uma variedade de significados e representações que determinada sociedade buscava realizar ao preparar e enterrar os seus mortos. Pesquisas realizadas a respeito das práticas funerárias comprovam a colocação, e demonstram bem essa variabilidade de práticas, sejam em enterramentos primários, secundários, individuais, 
coletivos, em feixes, urnas funerárias, ossos com pigmentação avermelhada, ossos cremados dentre outras características.

Sendo assim, analisar parcialmente os materiais provenientes das escavações do sítio Lajedo do Cruzeiro da cidade de Pocinhos/PB no sertão nordestino, provindo de um enterramento coletivo com diversas faixas etárias em contexto, que demonstraram marcas e sinais de manipulações intencionais no corpo do cadáver perimortem como uma prática cotidiana. Se comparando com as reflexões de Solari et al. (2017) e Strauss (2016), em que a prática de redução corporal no contexto funerário não é um acontecimento decorrente nos sítios préhistóricos do Brasil, e que não são facilmente observadas, podemos notar as variabilidades, ao mesmo tempo complexas na elaboração do ritual funerário até sua deposição final, e o que aquilo representa para aquele grupo.

\section{Referências}

ALCINA FRANCH, J. 1989. Arqueología Antropológica. Madrid, Akal.

CISNEIROS, D. 2004. Práticas funerárias na Pré-História do Nordeste do Brasil. Dissertação (Mestrado). Programa de Pós-Graduação em História, Universidade Federal de Pernambuco, Recife. $161 \mathrm{f}$.

CASTRO, V. M. C. de. 2009. Marcadores de identidades coletivas no Nordeste do Brasil. - Recife: O autor.

MARTIN, G. 2013. Pré-história do Nordeste do Brasil. - 4. ed., Recife: Hd. Universitária da UFPE,

MARTIN, G. 1994. Os Rituais Funerários na Pré-História do Nordeste. CLIO - Série Arqueológica, Recife, v. 1, n.10, p. 29-46.

RENFREW, C. \& BAHN, P. (1998). Arqueología: teorías, métodos y práctica. 2 ed., Trad. de M.J.M.Rial, Madrid, Akal.

RIBEIRO, M. S. 2007. Arqueologia das práticas mortuárias: uma abordagem historiográfica. São Paulo: Alameda.

SCHAEFER, M.; BLACK, S.; SCHEUER, L. 2009. Juvenile Osteology: A laboratory and field manual. Amsterdam Academic.

SILVA, J. A.; CARVALHO, O. A. de. 2013. Análise Arqueotanatológica de duas sepulturas infantis Sítio Justino-SE. Clio Arqueológica. v. 28. p. 74-104, Universidade Federal de Pernambuco.

SILVA, Sérgio F. S. M. da. 2007. Arqueologia das Práticas Funerárias: Resumo de uma estratégia. Revista Canindé. n. 10, Universidade Federal de Sergipe/MAX.

SOARES, T. M. 2019. Acompanhamentos funerários do Sítio Lajedo do Cruzeiro - Pocinhos / PB: identificação e caracterização das contas de colar e pingente. 56 f. Trabalho de Conclusão de Curso 
(Licenciatura em História) - Unidade Delmiro Gouveia - Campus do Sertão, Universidade Federal de Alagoas, Delmiro Gouveia.

SOLARI, A.; MARTIN, G.; SILVA, S. F. S. M da. 2016. A Presença Infantil no Registro Bioarqueológico no Sítio Pedra do Alexandre, Carnaúba dos Dantas, RN, Brasil. Fumdhamentos, v. XIII. p. 4-30.

SOLARI, A.; MONTEIRO DA SILVA, S. F. S. 2017. Sepultamentos secundários com manipulações intencionais no Brasil: um estudo de caso no sítio arqueológico Pedra do Cachorro, Buíque, Pernambuco, Brasil. Boletim do Museu Paraense Emílio Goeldi. Ciências Humanas, v. 12, n. 1, p. 135-155, jan.-abr. DOI: http://dx.doi.org/10.1590/1981.81222017000100008.

STRAUSS, A. 2016. Os padrões de sepultamento do sítio arqueológico Lapa do Santo (Holoceno Inicial, Brasil). Boletim do Museu Paraense Emílio Goeldi. Ciências Humanas, Belém, v. 11, n. 1, p. 243-276, jan.-abr.

STRAUSS, A. 2014. As práticas mortuárias dos primeiros sul-americanos. Arquivos do Museu de História Natural da UFMG, v. 23, p. 89-134.

STRAUSS, A. 2010. As práticas mortuárias dos caçadores-coletores pré-históricos da região de Lagoa Santa (MG): um estudo de caso do sítio arqueológico "Lapa do Santo". 2010. 703 f. Dissertação (Mestrado em Genética e Biologia Evolutiva) - Universidade de São Paulo, São Paulo.

TRIGGER, B. G. 2004. História do Pensamento Arqueológico. São Paulo: Odysseus Editora.

VERGNE, C. 2007. Complexidade social e ritualidade funerária em Xingó: apontamentos teóricos para compreensão das práticas mortuárias do sítio Justino, Canindé do São Francisco - SE. Canindé, Xingó, n. 9, p. 25-57. 